\title{
MARIA ISAURA PEREIRA DE QUEIROZ: UM OLHAR SOBRE A POLÍTICA ${ }^{1}$
}

\author{
Alice Beatriz da Silva Gordo Lang ${ }^{2}$
}

A Professora Emérita da Universidade de São Paulo, Maria Isaura Pereira de Queiroz, foi uma socióloga cuja obra é reconhecida nacional e internacionalmente. Pensou o Brasil em variados aspectos: o mundo rural, a cultura brasileira, a religião com destaque ao messianismo, o cangaço, a política apontando o papel do clientelismo, do coronelismo e das parentelas. Além da preocupação com a metodologia de pesquisa.

Maria Isaura nasceu em São Paulo em 1918 e faleceu nesta mesma cidade em 2018, depois de completar 100 anos. Fez os estudos elementares e cursou a Escola Normal no Instituto Caetano de Campos. Começou a lecionar. Pouco mais tarde, ingressou no curso de Ciências Sociais da Universidade de São Paulo. Mestres de diferentes nacionalidades, como Roger Bastide, Paul-Arbusse Bastide, Emilio Williams, Fernando de Azevedo, Florestan Fernandes, entre outros influenciaram sua formação. Foi a Paris estudar na École des Hautes Études, onde defendeu a tese "La Guerre Sainte au Brésil: le Mouvement Messianique du Contestado". Com Roger Bastide, ingressou no magistério na USP.

Em 1964, foi uma das fundadoras do Centro de Estudos Rurais e Urbanos - CERU, ligado à USP, centro que dirigiu por muitos anos e onde desenvolveu inúmeras pesquisas. Muitos são os pesquisadores e professores que devem a ela sua formação.

Por sua importante obra, em 1998, recebeu o Prêmio Almirante Álvaro Alberto, a mais alta condecoração atribuída a cientistas brasileiros. Foi a primeira mulher agraciada com o prêmio.

Estudou a sociedade brasileira com o olhar aguçado de socióloga, em diversas perspectivas que se enquadram como sociologia rural, sociologia da cultura, sociologia das religiões e sociologia política aqui destacada.

\footnotetext{
${ }^{1} \mathrm{O}$ artigo, com o título "Maria Isaura Pereira de Queiroz - anotações sobre a política", agora complementado, foi apresentado na Mesa Redonda "A construção dos paradigmas para a sociologia futura local - a obra de Maria Isaura Pereira de Queiroz', realizada no $19^{\circ}$ Congresso da Sociedade Brasileira de Sociologia, em Florianópolis, em julho de 2019.

${ }^{2}$ Alice Beatriz da Silva Gordo Lang é doutora em Sociologia pela USP e pesquisadora do CERU.
} 
Maria Isaura parte da análise de dados e situações, como era seu método: analisar, para explicar e depois concluir. Entre os vários temas sobre os quais Maria Isaura Pereira de Queiroz se debruçou, um é a política em uma visão sociológica. Uma de suas preocupações foi o desenvolvimento dos conceitos que envolvem os temas estudados, neste caso o mandonismo, o coronelismo, o republicanismo e a parentela, com base na análise da sociedade brasileira dos períodos da Colônia, do Império e da Primeira República. Criticou autores que partiam de um conceito para nele encaixar a realidade. Era por meio da análise da realidade que chegava aos conceitos e os desenvolvia.

Cabe observar a linguagem clara e correta de Maria Isaura, que torna facilmente compreensíveis as ideias que transmite. Em suas pesquisas, fez uso da obra de inúmeros historiadores e analistas dos períodos estudados, como José Maria Bello, Victor Nunes Leal, Sertório de Castro, Jean Blondel, Maria Sylvia Carvalho Franco. Para compreender uma situação ou o espírito de uma época, Maria Isaura recorreu a romancistas. Para o século XIX, a José de Alencar, Macedo, Machado de Assis, entre outros.

A proposta da autora foi sempre interpretar a política brasileira.

\section{Mandonismo}

Refiro-me primeiramente ao mandonismo, abordado por Maria Isaura Pereira de Queiroz na obra "O mandonismo local na vida política brasileira" (1969). Apontou a coerência interna da vida política nacional desde a Colônia, passando pelo Império e a Primeira República. Foi a coerência marcada pelo mandonismo local, que se transformou no coronelismo e que pouco a pouco foi cedendo espaço para o poder central fortalecido com a Revolução de 1930.

O mandonismo existiu desde o início da colonização, quando para povoar e colonizar a vasta terra descoberta, Portugal recorreu inicialmente a donatários e depois a proprietários particulares que deram origem às vilas e povoados. Era o proprietário o único defensor do poder local e a única autoridade. Foi o início do mandonismo que chegou ao Império, presente nos latifúndios, nos engenhos do Nordeste e nas fazendas do Vale do Paraíba.

O Rio de Janeiro era o centro do país. Era a sede do Império, com o fausto trazido com a Corte de D. João VI em 1808, fausto sustentado pela riqueza do café. O açúcar do Nordeste que fora a cultura mais rentável do país, e também o ouro das Gerais que se esgotara, cederam espaço ao café do Vale do Paraíba que era escoado pelo Rio de Janeiro. 
A política do Império se fazia por meio de dois partidos: o Liberal e o Conservador, embora houvesse o dito de que nada mais parecido a um liberal que um conservador quando no poder.

O Ministério era chefiado por um Chefe conservador ou um liberal, escolhido pelo Imperador. Fazendo uso do Poder Moderador, o Imperador dissolvia o ministério e o Parlamento e convocava novas eleições que faziam as câmaras segundo o partido do novo chefe escolhido. Liberais e conservadores alternavam-se no poder. O Imperador escolhia ora um chefe liberal, ora um conservador, fazendo uma alternância no poder. O Parlamento funcionava no Rio de Janeiro. Havia as Assembleias Provinciais e, nos municípios, a Câmara dos vereadores e os juízes de paz. Mas o poder repousava indiscutivelmente nas mãos dos mandões locais que influenciavam a escolha.

Contudo, a produtividade dos cafezais do Vale diminuía na metade do século XIX, exaurida pelo cansaço do solo. Nesse tempo, o café chegou ao Oeste Paulista, zona da terra roxa e se expandiu. A linha férrea da Inglesa unia o porto de Santos a Jundiaí. As fazendas prosperavam. Linhas e ramais foram estendidos pelos cafeicultores paulistas para escoar sua produção. Com o avançar das linhas férreas, novas zonas passaram a serem exploradas e cultivadas. Segundo se dizia, se os trilhos inicialmente traziam o café, depois eram os trilhos que levavam o café para novas plantações.

O Segundo Império assistiu à luta pela emancipação dos escravos, questão fundamental nesse tempo. A lavoura brasileira apoiava-se no braço escravo. Dom Pedro II, atendendo a reivindicações da Inglaterra, assinou em 1850 a Lei Euzébio de Queiroz que proibia o tráfico dos escravos. Foi o desastre dos engenhos do nordeste. A zona cafeeira do Vale do Paraíba precisava de braços e passou a comprar escravos do Nordeste. Movimentavam-se produtores agrícolas e políticos com a questão da abolição dos escravos. Grupos favoráveis e grupos desfavoráveis.

Os cafeicultores do Oeste Paulista, também contavam com a mão de obra escrava. Viam se aproximar o fim da escravidão. Iniciativas foram feitas para a substituição do escravo por mão de obra livre. A primeira tentativa foi a do Senador do Império Nicolau de Campos Vergueiro, na Fazenda Ibicaba, em Limeira. Um colono suíço, Thomas Davatz, aliás, mestre escola, contou as desventuras dos colonos dessa fazenda no livro "Memórias de um colono no Brasil" " . A iniciativa não deu certo, mas mostrou o caminho que foi seguido pelos paulistas. $\mathrm{O}$ governo da Província de São Paulo tomou iniciativas para atrair imigrantes.

\footnotetext{
${ }^{3}$ Davatz, Thomas (1858/1980).
} 
Outra lei do Império, a Lei do Ventre Livre (1871), determinou que os que nasciam não seriam mais escravos. Essa lei adiou por uns tempos o problema, mas finalmente, em 1888, foi assinada a Lei Áurea, pondo término à escravidão. A lavoura se desorganizou, mas não a paulista que já contava com mão de obra livre. As províncias do Ceará e Amazonas haviam se antecipado, libertando seus escravos em 1885.

\section{No século XIX o mandonismo se transforma no coronelismo}

O coronelismo é discutido por Maria Isaura Pereira de Queiroz em um texto tornado um clássico sobre o tema: “O coronelismo numa interpretação sociológica”, de 1982.

Os municípios tinham nos grandes fazendeiros os chefes locais, os mandões, muitos dos quais receberam o título de Coronel da Guarda Nacional - eram coronéis da reserva.

A Guarda Nacional foi criada no período da Regência, em 1831. Era uma organização paramilitar criada para garantir a segurança pública, sendo subordinada ao Ministro da Justiça e aos Presidentes das Províncias. Havia os corpos efetivos da Guarda Nacional e os da Reserva. Havia uma estrutura, coronéis maiores e menores, também o tenente-coronel , o major, o capitão. Os membros da guarda eram recrutados entre os cidadãos eleitores e seus filhos, com uma renda de 200 mil reais nas cidades e 100 mil reais nas demais regiões. A patente de Coronel da reserva era atribuída aos grandes proprietários, os mandões locais, e passou a ser equivalente a um título nobiliárquico.

Era entre os coronéis que se davam as verdadeiras lutas pelo poder. Em uma desavença, chamado imperador ou o ministério a intervir, estes aguardavam a luta se resolver e davam a palma ao vencedor. O poder central não ousava desafiar os coronéis. Mostra Maria Isaura que o poder, efetivamente, estava nas mãos dos coronéis, que faziam os deputados. Nas eleições, votavam os alfabetizados, incluindo os sitiantes e o pessoal do comércio. $\mathrm{Na}$ época eleitoral, os cabos eleitorais visitavam os eleitores, levando presentes juntamente com a cédula de votação.

O poder do coronel era tanto maior, quanto mais votos detinha. Por outro lado, o sitiante e outros tinham no coronel seu defensor, seu suporte para necessidades. A contrapartida era o voto no candidato designado pelo coronel. Era o dom e contra-dom.

O coronelismo marcava a estrutura social, alocando os indivíduos em relação ao coronel. Sou primo, sou parente do coronel Fulano indicava a posição social do indivíduo ligado de qualquer forma à parentela do coronel. Sou gente do coronel indicava a posição do sitiante ou agregado a determinado coronel.

O coronel era o chefe de uma parentela, assim definida por Maria Isaura: 
Entendemos por 'parentela' brasileira um grupo de parentesco de sangue formado por várias famílias nucleares e algumas famílias grandes (isto é, que ultrapassam o grupo pai-mãe-filhos), vivendo cada qual em sua moradia, regra geral economicamente independentes; as famílias podem se encontrar dispersas a grandes distâncias umas das outras; o afastamento geográfico não quebra a vitalidade dos laços, ou das obrigações recíprocas. (1982, p.165).

Integravam a parentela os parentes por casamento e aqueles unidos pelo compadrio.

O coronelismo teve seu florescimento na Primeira República, marcando a política brasileira.

\section{Republicanismo e parentela}

Para falar da luta pela República e também das parentelas, forte elemento na política do período, recorro a um trabalho de Maria Isaura Pereira de Queiroz - “O Partido Republicano Paulista durante o Império", um trabalho ainda inédito e inconcluso.

Em meados do século XIX, o descontentamento com o poder central se acentuava no Oeste Paulista. As rendas auferidas na Província iam para a capital em forma de impostos que sustentavam o fausto da Côrte e pouco revertiam para a Província. Brotou a ideia do federalismo, brotou a ideia do republicanismo.

No Rio de Janeiro, liberais extremados haviam fundado o Partido Radical, adotando o ideário republicano. Foi no Rio, em 1870, que foi lançado o Manifesto Republicano, com repercussão nas demais províncias, juntamente com o jornal “A República”. Assinaram o manifesto cinquenta e seis cidadãos, entre esses os paulistas Rangel Pestana e Miranda de Azevedo. O Manifesto terminava com o grito significativo: "Somos da América e queremos ser americanos".

Repercutiu profundamente na Província de São Paulo, onde os interesses dos cafeicultores eram contrariados pelo centralismo, o que os levava a desejar o federalismo. No Rio de Janeiro, o movimento teve pouca repercussão e curta duração, talvez obscurecido pela ideia abolicionista que se expandia.

Foi Américo Brasiliense, político liberal, que em São Paulo tomou a iniciativa de congregar adeptos do republicanismo, em uma reunião em sua casa, em 1872. Decidiram os presentes que seria organizada uma Convenção no ano seguinte, na cidade de Itu. A reunião foi dirigida por João Tibiriçá Piratininga, presidente do Clube Republicano daquela cidade e com a presença de representantes de várias municipalidades. Foi no dia 18 de abril de 1873, quando 
foi fundado o Partido Republicano Paulista. O congresso contou com a presença de representantes de vinte e nove localidades, lançou um manifesto sobre a questão servil e elegeu a primeira comissão permanente.

Clubes e núcleos republicanos esparsos e também clubes radicais aderiram. São Paulo foi a única província que teve um partido republicano organizado. Congressos deveriam organizar-se todos os anos, lançando um manifesto sobre uma questão candente.

Os republicanos paulistas dedicaram-se com afinco ao movimento que ficou chamado A Propaganda Republicana ${ }^{4}$. Elaboraram um Programa e recorreram a variados meios para difundir a ideia republicana: comícios, conferências, imprensa, publicações e participação de candidatos em eleições. O jornal A Província de São Paulo, fundado em 1875 por Azevedo Marques e dirigido por Américo de Campos e Rangel Pestana, era o órgão oficioso do PRP noticiando os avanços da ideia republicana.

Candidatos republicanos participavam das eleições. Alguns municípios, conseguiram eleger vereadores. Para a Assembleia Provincial, tiveram de fazer acordos e a chamada "transação de votos" com um dos partidos monárquicos, o Conservador ou o Liberal, para eleger representante. Usando esse expediente, conseguiram também eleger, como deputados à Câmara Geral, Prudente de Morais e Campos Salles em 1885.

Os republicanos paulistas adotaram o princípio da disciplina partidária. O candidato assumia um compromisso com o partido e a ele prestava contas de seu mandato.

$\mathrm{O}$ aumento dos quadros republicanos foi lento nos primeiros anos, mas aumentou significativamente no ano de 1885, com a queda do Gabinete Liberal.

Nas outras províncias, o movimento republicano só se intensificou depois da abolição.

Nas palavras de Maria Isaura:

Se as correntes de ideias da época, a abolição e a questão militar explicam a proclamação da República, explicarão também a existência e persistência deste partido na Província de São Paulo quando, mesmo na Côrte, centro muito mais adiantado que qualquer outro do país, na época, apenas surgiam núcleos isolados e efêmeros? (p.27).

É preciso não confundir a disseminação do ideal republicano com a persistência do PRP. Se a primeira se dava ao acaso das influências, a segunda

\footnotetext{
${ }^{4}$ Ver Lang, 1995.
} 
era um fato planejado e sistematizado, apresentando-se como resultado de um pensamento objetivamente orientado. (p. 31).

Maria Isaura mostra a influência do republicanismo da Argentina por meio das conferências de Quintino Bocaiúva, dos Estados Unidos, país novo e republicano, pelo progresso alcançado, da França, luzeiro do mundo - onde se instalava a Terceira República.

O sistema republicano encontrou adeptos entusiasmados entre os novos bacharéis, os cadetes da Escola Militar e os estudantes.

\section{A Faculdade de Direito de São Paulo}

A Faculdade de Direito de São Paulo foi berço do republicanismo, mas não a do Recife, fundadas pelo mesmo decreto de 1827.

Quase todos os políticos paulistas do Império e da Primeira República, assim como de outros estados, estudaram na Faculdade de Direito e lá se formaram no liberalismo. Prudente de Moraes, Manoel Moraes Barros, Campos Salles, Américo Brasiliense, Rodrigues Alves, Adolpho Gordo, entre tantos outros.

Era uma escola de leis, era uma escola de política. Prudente de Moraes e Campos Salles, formados na Faculdade de Direito, foram deputados pelo Partido Liberal, antes de fundado o Partido Republicano.

Pensando na influência dos jovens na República, Maria Isaura mostra que os bacharéis Américo Brasiliense, Rangel Pestana, Campos Salles, Prudente de Moraes, Bernardino de Campos eram moços que em 1873 tinham entre vinte e sete e trinta e sete anos. Por meio dos romancistas do período, mostra que o conceito de idade - o conceito de moço e de velho - varia com o grupo, o tempo e o lugar.

Nos romances de Macedo e Alencar, mocidade e velhice estão bem caracterizadas. A idade da inexperiência, das paixões, dos entusiasmos, é a idade dos estudantes estouvados e das mocinhas românticas de Augusto e da Moreninha, do romance 'Til', dos 15 aos 21 anos. Em 'O Tronco do Ipê', Mário, voltando da Europa onde se formara, apresentava-se, aos 20 anos, como um homem de feições graves, ao qual atribuem intenções de se candidatar a deputado nas eleições daquele ano; na 'Moreninha', o pai de Augusto, que tem 50 anos, é descrito como se fora um patriarca. (p.34). 
Bacharéis gaúchos, formados na Faculdade de Direito de São Paulo, voltaram a sua Província depois de formados. Participaram da formação do Partido Republicano que, entretanto, tinha uma conotação positivista, de acordo com os grandes líderes do Rio Grande, Júlio de Castilho e Assis Brasil. O Partido Republicano Riograndense, PRR, foi fundado em 1882, com uma orientação positivista, seguindo a máxima de Augusto Comte: Ordem e Progresso.

Maria Isaura observa que "Mocidade e bacharelismo não explicam, pois, a existência do PRP em São Paulo; em todo Brasil havia bacharéis e mocidade, metidos ou não na política, e só em São Paulo havia um partido republicano.” (p.39)

\section{Uma parentela entre outras}

$\mathrm{Na}$ época, eram os laços de parentesco que prendiam mais fortemente os indivíduos uns aos outros. Mostra Maria Isaura o importante papel das parentelas na política do período, importância que prosseguiu depois de proclamada a República. A parentela, como organização familiar, foi o caráter que marcou a vida rural brasileira desde os tempos coloniais, sendo ligada ao latifúndio. Os laços de parentesco prendiam os indivíduos uns aos outros, seja por laços sanguíneos ou de aliança, seja por laços espirituais, o compadrio. A parentela era um grupo familiar, social e político, que existiu também no meio urbano.

Focalizo uma importante parentela do período, a de Prudente de Moraes ${ }^{5}$. Prudente José de Moraes Barros foi o grande chefe republicano, líder de uma extensa parentela

Uma interessante história, que se reporta à saga do português Antonio José da Silva, que fugiu do Porto com doze anos, embarcou em um navio que partia e veio como clandestino para o Brasil, sendo descoberto já em alto mar. No Rio de Janeiro, foi levado a uma praça onde escravos eram vendidos. Foi comprado por um fazendeiro de Itu, o Capitão Caetano José Gomes Carneiro, que o educou e fez dele administrador de sua fazenda. Tornou-se administrador de outras fazendas, entre elas a Morro Azul em Limeira. António José da Silva, simpático e benquisto, tornara-se conhecido como Boava Gordo (Boava, porque português, e Gordo, pelo porte físico avantajado) acrescentando Gordo ao seu sobrenome. Faleceu o proprietário de uma fazenda onde Boava trabalhava e a viúva, Francisca de Assis Figueiredo, propôs casamento ao administrador. Casado, António José tornou-se vereador de Itu e tenente coronel da Guarda Nacional. Faleceu a viúva.

${ }^{5}$ Lang, 2019. 
António José decidiu visitar a fazenda do seu protetor, onde havia começado a vida no Brasil. Conheceu a neta do Capitão Carneiro, a jovem Anna Brandina de Barros, e se encantou. Casaram-se. Tiveram cinco filhas e dois filhos.

Conta-se que António José ajudara os irmãos Moraes Barros para que se formassem. Poderiam ser sobrinhos de Anna Brandina de Barros. Já bacharéis e iniciados nas lides políticas, os irmãos se casaram com duas filhas de António José: Prudente com Adelaide Benvinda e Manuel com Maria Ignês. Um foi o primeiro presidente republicano e o outro, senador. Outra irmã, Rita, casou-se também com um político, o deputado Antônio Carlos Ferraz de Salles. O caçula da família era Adolpho Gordo, que se formou também na Faculdade de Direito de São Paulo e logo ingressou na política, militando na Propaganda Republicana. Adolpho Gordo casou em primeiras núpcias com uma neta do Senador Vergueiro e em segunda com Albertina Vieira de Carvalho, esta filha de um monarquista, professor da Faculdade de Direito.

Campos Salles era parente de Anna Brandina. Formaram uma família imensa, todos com vários filhos, inúmeros sobrinhos, vários compadres. Uma grande parentela, com muitos políticos.

Estava formada uma parentela republicana, atuante na luta pela mudança do regime e depois na Primeira República. Prudente de Moraes era o chefe incontestado. Foi Presidente da Província, Presidente da Assembleia Constituinte Republicana e o primeiro presidente civil da República.

Ao lado dessa parentela, havia outras também no Estado de São Paulo, como a de Rodrigues Alves, fazendeiro de Guaratinguetá, no Vale do Paraíba. Conselheiro do Império, que abraçou o republicanismo. Rodrigues Alves foi constituinte de 1891, Presidente da Província de São Paulo, Presidente da República. Importante papel foi também desempenhado na Primeira República pela parentela de Rodrigues Alves, que incluía inúmeros políticos como Altino Arantes, governador do Estado de São Paulo de 1916 a 1920 e muitos outros. Parentelas havia em todo o Brasil, com as mesmas características: grupo de parentesco, grupo econômico e grupo político.

\section{Mudanças e permanências}

Com a República, mudanças se impuseram como o sistema de votação, a diminuição do poder dos municípios em favor dos Estados. Mas o poder continuou na mão dos proprietários rurais. Eram eles que faziam os deputados. Se antes, os mandões iam à votação com a família, passaram a comparecer também com os agregados, que contavam com os coronéis como apoio 
certo para suas necessidades. $\mathrm{O}$ voto era nada mais que o dom e contra-dom. Elegiam seus deputados.

O centro da política continuava, apesar das determinações da lei, a ser o município e, dentro dele, o coronel. O mandonismo prosseguia, apoiado nos municípios, a despeito da maior centralização do poder dos estados, pretendida pela República.

Diz Maria Isaura:

Mesmo num Estado como S. Paulo, glorioso de possuir um partido republicano organizado, o mais antigo do país, o P.R.P., diretor da política estadual, estava ela, na verdade, na mão das influências municipais; certa dissimulação, porém, tentava encobrir este aspecto do mandonismo local, que tresandava ainda a tempos imperiais e não condizia com as liberdades republicanas, mas a verdade transparecia.(p. 89).

O coronelismo chegou à República, com os vários níveis de coronéis. O maior dos coronéis foi o gaúcho Pinheiro Machado.

Um caso exemplar de mandonismo é o do Padre Cícero, no Ceará. Uma influência enorme no eleitorado do Ceará e na condução dos negócios de Juazeiro. Padre Cícero desafiava as ordens do poder central, como no caso de dar guarida aos revolucionários da Coluna Prestes, quando a marcha passou por Juazeiro.

O crescimento demográfico, a urbanização e a industrialização, processos que se desenvolviam em ritmo diverso conforme o momento histórico e a região, foram enfraquecendo a estrutura coronelista.

Coronelismo e parentela foram os pilares do Império e da Primeira República.

Questão que se coloca: o papel das parentelas e do clientelismo terminou na Primeira República ou aparece, ainda hoje, repaginado como familismo e nepotismo?

\section{Referências bibliográficas}

DAVATZ, Thomaz. Memórias de um colono no Brasil. Chur (Suiça), 1858. São Paulo: Edusp/Itatiaia, 1980.

LANG, Alice Beatriz da Silva Gordo. “Arquivo Adolpho Gordo”. Palestra proferida no Centro de Memória Unicamp em 01/08/2019.

LANG, Alice Beatriz da Silva Gordo. A propaganda republicana na Província de São Paulo. São Paulo: CERU, 1995. (Coleção Textos, série 2, número 6). 
QUEIROZ, Maria Isaura Pereira de. O mandonismo na vida política brasileira. São Paulo: Instituto de Estudos Brasileiros, Universidade de São Paulo, 1969 (14).

QUEIROZ, Maria Isaura Pereira de. "O clientelismo numa interpretação sociológica”. In: Fausto, Boris (Org.). III O Brasil Republicano. I Estrutura de poder e economia (1889-1930). $3^{\text {a }}$ ed. São Paulo: Difel/Difusão Editorial, 1982. p. 153-190.

QUEIROZ, Maria Isaura Pereira de. “O Partido Republicano Paulista durante o Império". Trabalho inédito e inconcluso.

TV Unicamp e Centro de Memória

Série Adolpho Gordo, memórias de um senador paulista.

Vídeo: Adolpho Gordo por Alice Lang

Campinas, 2019. 